\title{
DIREITO PENAL SIMBÓLICO NA MODERNIDADE LÍQUIDA: ENSAIO CRIMINOLÓGICO NA PERSPECTIVA BAUMANIANA
}

\section{Igor Eduardo dos Santos Araujo}

Acadêmico de Direito da Universidade do Estado da Bahia (UNEB). Servidor do Poder Judiciário da União.

E-mail: igorsalvador@yahoo.com.br

\section{RESUMO}

A obra do sociólogo polonês Zygmunt Bauman possui como nota característica a tese de que vivemos em uma Modernidade Líquida, marcada pela fluidez e instabilidade das instituições e das relações. Nesse contexto, de notada fragmentação, individualismo e isolamento, emerge um cenário de insegurança generalizada, que tem por pano de fundo o crescimento da criminalidade, levando ao aumento dos índices de encarceramento e a um endurecimento das normas penais, como fruto de um processo que a doutrina denomina de "Direito Penal Simbólico", que ignora as reais causas históricas, sociais e políticas do fenômeno crime. 0 presente trabalho traça uma relação entre os postulados teóricos de Bauman e algumas proposições criminológicas, tendo em vista a construção de um posicionamento crítico e dialógico para a compreensão da conjuntura posta. Aborda-se o direito de emergência e a legislação penal simbólica em diálogo com as lições de Bauman sobre a ética da Modernidade.

PALAVRAS-CHAVE: Direito Penal Simbólico. Modernidade Líquida. Insegurança. Criminologia. 


\section{INTRODUÇÃO}

$\mathrm{Na}$ sociedade contemporânea, convive-se com um sentimento constante de insegurança. Embora tenham se disseminado os muros e as grades, a par dos mecanismos de monitoramento eletrônico, a sensação de insegurança é generalizada.

Diante do fenômeno crescente da criminalidade, o senso comum costuma apontar como soluções o aumento do número de prisões e da intensidade das penas aplicadas aos condenados. A verdade, entretanto, é que, não obstante o progressivo aumento dos índices de encarceramento e a criação de novos tipos penais, tentando abarcar cada novo delito que a criatividade humana é capaz de desenvolver, tem se revelado inócua a tarefa de fazer frente ao fenômeno da insegurança, o que é - ressalte-se - um paradoxo diante da promessa da Modernidade de oferecer paz e segurança.

Diante de tal contexto, as lições do sociólogo polonês Zygmunt Bauman revelam uma receita fundamental na compreensão do quadro atual. Para Bauman, o mundo atravessa uma ultramodernidade, a qual ele denomina de líquida, dada a fluidez das instituições, a instabilidade das relações e a insegurança generalizada que a caracterizam. De acordo com o pensamento baumaniano, longe de ser uma mera consequência indesejável, o aumento da criminalidade e da insegurança seriam efeitos necessários do ethos da sociedade de consumo.

O presente ensaio busca, com isso, promover um diálogo entre a proposta sociológico-filosófica de Bauman e alguns postulados da criminologia crítica, especialmente no que tange ao Direito Penal Simbólico, formulado a partir de uma cultura de emergência penal.

Parte-se da definição conceitual de "Modernidade Líquida", prosseguindo pela discussão sobre o problema da insegurança, e dos mecanismos que a fomentam, até atingir a questão da produção de um Direito Penal Simbólico, em resposta à sensação de insegurança.

Sem a pretensão de esgotar a temática posta, o presente trabalho cuida de oferecer um contributo à compreensão da realidade contemporânea, com suas contradições éticas, lançando um olhar reflexivo sobre a seara criminológica. 


\section{A MODERNIDADE LÍQUIDA}

O advento da Modernidade é tradicionalmente apontado como grande marco de transição da humanidade entre a cultura dita - de forma imprópria - antiga ou arcaica e a cultura dita moderna, marcadamente cientificista e tecnicista.

Não se trata, aqui, de mera passagem tempo, numa perspectiva cronológica, mas de uma verdadeira ruptura epistemológica, promovida mediante a promessa de que a "racionalidade instrumental" (expressão própria do pensamento weberiano) dos novos tempos viria de encontro a dois grandes anseios da humanidade: paz e segurança. Em tal contexto histórico, leciona Zygmunt Bauman que:

[...] a elite escritora da Europa Ocidental e seus pontos de apoio em outros continentes consideravam que seu próprio modo de vida constituía uma ruptura radical na história do mundo. Uma fé quase inquestionada na superioridade de sua própria forma de vida sobre todas as formas alternativas - contemporâneas ou passadas - lhe permitia tomar a si mesma como ponto de referência para a interpretação do télos da história. (BAUMAN, 2010, p. 155).

Se o homem, na Antiguidade e mesmo na Era Medieval, possuía um sentimento de pertencimento ao seu tempo e lugar, na Modernidade o homem assumiu uma postura de "senhor da história", como se a técnica ora desenvolvida fosse capaz de conduzir à solução de todos os problemas e ao nascimento de uma nova era, superior às demais.

Para Bauman, o traço distintivo da Modernidade residiria na dissociação da tradicional perspectiva de tempo e espaço:

De fato, a modernidade é, talvez mais que qualquer outra coisa, a história do tempo: a modernidade é o tempo em que o tempo tem uma história. Se pesquisarmos em livros de história a razão por que espaço e tempo, outrora mesclados nos afazeres da vida humana, se separaram e se afastaram no pensamento e prática dos homens, encontraremos com frequência histórias edificantes de descobertas realizadas pelos valentes cavaleiros da razão - filósofos intrépidos e cientistas corajosos. Aprendemos sobre astrônomos que mediam distâncias e a velocidade dos corpos celestes, sobre Newton calculando as relações exatas entre a aceleração e a distância percorrida pelo "corpo físico" e seus enormes esforços para expressar tudo isso em números - as mais abstratas e objetivas de todas as medidas imagináveis; ou sobre Kant, impressionado por suas realizações a ponto de conceber espaço e tempo como duas categorias transcendentalmente separadas e mutuamente independentes do conhecimento humano. (BAUMAN, 2001, p. 129-130).

A perspectiva espaço-temporal da Modernidade terminou por desenvolver um ethos próprio, absolutamente distinto da ética comunitária das sociedades tradicionais, vez que a ética moderna é essencialmente individualista e fragmentária, como aponta Bauman (1997, p. 
19): “[...] os desenvolvimentos modernos forçaram os homens e as mulheres à condição de indivíduos que viram suas vidas fragmentadas, separadas em muitas metas e funções soltamente relacionadas, cada uma a ser buscada em contexto diferente e segundo pragmática diversa".

A lógica fragmentária da vida humana, adotada neste novo período, refletiria na fragmentação do conhecimento, cuja expressão no campo jurídico seria a gênese da corrente intitulada de Positivismo Jurídico, que pretendia produzir e interpretar um direito dissociado das questões de ordem moral, mas, também, desconectado do contexto histórico, social e valorativo em que fora produzido.

É justamente nesse contexto que são moldadas as normas jurídicas da Modernidade. No afã de sepultar os traços característicos do Medievo - período histórico em que a moral era notadamente marcada pela influência religiosa - os teóricos do Positivismo Jurídico propuseram um direito axiologicamente neutro, cuja imperatividade decorreria exclusivamente da presença do fundamento de validade da norma na estrutura do ordenamento jurídico. A tal despeito, prossegue Bauman aduzindo que:

\begin{abstract}
Esta é a razão pela qual legisladores e pensadores modernos sentiram que a moralidade, antes de ser "traço natural" da vida humana, é algo que se precisa planejar e inocular na conduta humana; e essa é a razão pela qual tentaram compor e impor uma ética onicompreensiva e unitária [...]. Criam honestamente que o vazio, deixado pela agora extinta ou ineficaz supervisão moral da Igreja, podia e devia preencher-se com um conjunto, cuidadosa e habilmente harmônico, de regras racionais; que a razão podia fazer o que a crença não estava mais fazendo; que com seus olhos, tornados largamente abertos, e com suas paixões, postas em repouso, os homens poderiam regular seus relacionamentos mútuos não menos, e talvez mais e melhor (de maneira mais "civilizada", pacífica e racional) que na época em que se viam "cegados" pela fé e em que seus sentimentos, não dominados e não domesticados, corriam selvagens. Em linha com essa convicção, fizeram-se sem cessar tentativas de construir um código moral que não mais se escondendo sob mandamentos de Deus - proclamasse em alto e bom som corajosamente sua proveniência "feita pelo homem" e apesar disso (ou antes, graças a isso) fosse aceito e obedecido por "todos os seres humanos". (BAUMAN, 1997, p. 11).
\end{abstract}

O Positivismo Jurídico pode ser apontado, então, como a transposição valorativa da Modernidade para a ciência jurídica. Não à toa, as primeiras legislações modernas foram produzidas com caráter notadamente liberal e individualista e com a pretensão de serem aplicadas sem qualquer incidência da realidade fático-valorativa.

Desse modo, a nota distintiva do Positivismo Jurídico seria a assimilação do ideal moderno de segurança, mediante a proposição de um modelo altamente norteado pelo propósito de segurança jurídica. 
As contradições da Modernidade, entrementes, não tardariam a serem postas em exposição: a pretensa superioridade cultural europeia não se sustentaria sem a exploração imperialista dos povos que - paradoxalmente - eram tidos por inferiores e os dilemas éticos, transpostos ao plano das nações, resultariam nos horrores de duas grandes guerras e no morticínio generalizado que Hannah Arendt batizaria de "banalização do mal".

Tal contexto histórico conduziu a um processo de questionamento teórico dos pilares modernos, ante a sua incapacidade fática de produzir a paz e segurança propagandeadas. No dizer de Bauman:

Precisamos aprender a viver sem essas garantias e conscientes de que nunca se oferecerão essas garantias - de que uma sociedade perfeita, assim como um ser humano perfeito, não é perspectiva viável, ao passo que tentativas de provar o contrário acabam sendo mais crueldade que humanidade e certamente menor moralidade. (BAUMAN, 1997, p. 16).

O novo recorte epistemológico, construído a partir da crítica da Modernidade e do diálogo com valores da pré-Modernidade, tem produzido um cenário de ultramodernidade ou, como prefere a maioria dos comentadores, de pós-modernidade.

Não há, ainda, clareza acerca do cenário dito pós-moderno, mas Zygmunt Bauman aponta uma série de notas distintivas que o levam a dividir a Modernidade em dois períodos, os quais chama de Modernidade pesada e Modernidade líquida:

Em suma, o principal significado da ideia de Pós-Modernidade é que ela é algo diferente da Modernidade. Ele indica, portanto, que a Modernidade já não é a nossa forma de vida, que a Era Moderna está encerrada, que ingressamos hoje em outra forma de viver.

[...] A partir dessa conclusão, só havia um pequeno passo a se dar para definir como "líquido-moderna" aquela forma emergente de vida, aquela forma que era moderna de uma maneira radicalmente diferente daquilo que havíamos testemunhado (e de que havíamos participado) antes. Uma forma de vida digna de nota sobretudo por sua reconciliação com a ideia de que, assim como todas as substâncias líquidas, também as instituições, os fundamentos, os padrões e as rotinas que produzimos são e continuarão a ser como estas, "até segunda ordem"; que elas não podem manter e não manterão suas formas por muito tempo. Em outras palavras, que entramos em um modo de viver enraizado no pressuposto de que a contingência, a incerteza e a imprevisibilidade estão aqui para ficar. Se o "fundir a fim de solidificar" era o paradigma adequado para a compreensão da modernidade em seu estágio anterior, a "perpétua conversão em líquido", ou o "estado permanente de liquidez", é o paradigma estabelecido para alcançar e compreender os tempos mais recentes - esses tempos em que nossas vidas estão sendo escritas. (BAUMAN, 2010, p. 11-13).

Na perspectiva Baumaniana, tratar-se-ia da transição da era do hardware para a era do software. Ocorre que a perspectiva das rápidas e constantes mudanças, aliadas a um 
cenário de constante incerteza e fluidez, longe do corolário fundamental da Modernidade com sua promessa de paz e segurança, tem conduzido a um cenário de insegurança generalizada.

\section{DESEJO DE SEGURANÇA}

O desejo de segurança tem sido uma constante no pensamento moderno, o que explica a preferência, na Modernidade Jurídica, por modelos normativos rígidos e inflexíveis. $\mathrm{O}$ direito, como um todo, e, em particular, o direito penal teriam papel fundamental no processo de pacificação social, estabelecendo limites à conduta humana, cuja transgressão seria capaz de invocar o poder sancionador do Estado.

A aplicação da lei penal, deveria, de acordo com a racionalidade jurídica, constituir medida de ultima ratio, aplicável apenas quando os demais ramos do direito se revelassem incapazes de sancionar a conduta reprovável e adstrita à observância das garantias e liberdades fundamentais.

Observa-se, entretanto, um movimento pendular no que tange ao binômio segurançaliberdade; tanto mais se busca segurança, maior sacrifício das liberdades e tanto mais liberdade, menor a oferta de segurança:

\footnotetext{
A promoção da segurança sempre requer o sacrifício da liberdade, enquanto esta só pode ser ampliada à custa da segurança. Mas segurança sem liberdade equivale a escravidão (e, além disso, sem uma injeção de liberdade, acaba por ser afinal um tipo muito inseguro de segurança); e a liberdade sem segurança equivale a estar perdido e abandonado (e, no limite, sem uma injeção de segurança, acaba por ser uma liberdade muito pouco livre). (BAUMAN, 2003, p. 24).
}

Talvez, por isso mesmo, do ponto de vista simbólico, a grande representação do desejo moderno de segurança resida na figura do panóptico, originalmente pensado pelo liberal Jeremy Bentham e popularizado na obra de Foucault.

O panóptico é um modelo arquitetônico projetado para maximizar os esforços no controle e vigilância de um determinado grupo de pessoas. Trata-se de uma construção circular, com um ponto central de vigilância, que visa a incutir nas pessoas a sensação de estar sendo permanentemente vigiadas. O modelo foi pensado para aplicação em escolas, hospitais, gestão do chão de fábrica ou de unidades prisionais, espaços onde foram popularizadas.

A sociedade moderna se constitui em um grande panóptico, na medida em que o desejo de segurança se traduz no aumento da vigilância e na proporcional redução das 
liberdades individuais. Como dito alhures, há uma balança onde segurança e liberdade tentam estabelecer algum equilíbrio.

Ocorre que, como aponta Bauman, o panóptico se torna não apenas a prisão daqueles que são objeto de vigilância e punição, mas, também, daqueles que supervisionam a pena:

\begin{abstract}
E assim durante a maior parte de sua história a modernidade se desenvolveu sob os auspícios do poder "panóptico", obtendo a disciplina pela vigilância contínua. O princípio essencial do panóptico é a crença dos internos de que estão sob observação contínua e de que nenhum afastamento da rotina, por minúsculo e trivial que seja, passará despercebido. Para manter essa crença, os supervisores tinham que passar a maior parte do tempo nos postos de observação, do mesmo modo que os pais não podem sair de casa por muito tempo sem temer travessuras dos filhos. O modelo panóptico de poder prendia os subordinados ao lugar, aquele lugar onde podiam ser vigiados e punidos por qualquer quebra de rotina. Mas também prendia os supervisores ao lugar, aquele de onde deviam vigiar e administrar a punição. (BAUMAN, 2003, p. 35).
\end{abstract}

Essa é a grande contradição do desejo de segurança na modernidade: a busca constante por segurança conduz a um grau mais elevado de controle que, por seu turno, retroalimenta a insegurança.

A tal despeito, observa-se que, no caso brasileiro, o aumento desmedido da população carcerária tem se revelado uma medida, no mínimo, insuficiente e, em verdade, inadequada na contenção dos índices criminalísticos e na capacidade de proporcionar a pretendida pacificação social.

Citando o exemplo da Grã-Bretanha, Bauman expõe como o número de delitos cresceu, de 1981 a 1993, de 2,9 para 5,5 milhões; em apenas três anos, aponta, a população carcerária havia subido de 40.606 para 51.243, e conclui:

\footnotetext{
Durante os últimos vinte e cinco anos, a população dos encarcerados e de todos os que obtêm a sua subsistência da indústria carcerária - a polícia, os advogados, os fornecedores de equipamento carcerário - tem crescido constantemente. O mesmo ocorreu com a população de ociosos - exonerados, abandonados, excluídos da vida econômica e social. Consequentemente, como seria previsível, aumentou o sentimento popular de insegurança: atualmente, $85 \%$ da população da Grã-Bretanha acham que, há 30 anos, era seguro caminhar pelas ruas à noite, mas $95 \%$ acham que, hoje em dia, não é seguro. (BAUMAN, 1998, p. 49).
}

Os dados apresentados coincidem, empiricamente, com a realidade brasileira, no que diz com a indústria do encarceramento e no que diz com a retroalimentação da insegurança. Embora o Brasil possua hoje a quarta maior população carcerária do mundo, a sensação de insegurança não regride e, a revés, a população reclama por mais e mais prisões. 
A realidade social citada pelo autor aponta, ainda, para o problema do crescimento ostensivo do número de ociosos, aqueles indivíduos excluídos da vida econômica e social, à margem da sociedade de consumo, portanto. Este outro crescimento nada tem de acidental, mas é outra consequência previsível da ética do mundo de consumidores em que vivemos.

Ao citar a população compulsória de ociosos, se chama atenção para o agravamento da questão posta em relação ao exército de reserva, na medida em que, conforme Bauman, já não mais se fala em fim do desemprego, mas em "racionalizar" a força de trabalho, sinônimo de reduzi-la ou substituí-la por mão de obra mais submissa e menos dispendiosa, dando conta de que o desemprego será um fenômeno com o qual se terá que conviver continuamente.

Desta forma, explica, a criminalidade cada vez maior não seria efeito de um mal funcionamento da sociedade (ou resultado de fatores externos), mas, a contrario sensu, um produto inevitável da sociedade de consumo; aqui, a lição de Bauman tem um toque profético ao concluir que:

[...] os "excluídos do jogo" (os consumidores falhos - os consumidores insatisfatórios, aqueles cujos meios não estão à altura dos desejos, e aqueles que recusaram a oportunidade de vencer enquanto participavam do jogo de acordo com as regras oficiais) são exatamente a encarnação dos "demônios interiores" peculiares à vida do consumidor. Seu isolamento em guetos e sua incriminação, a severidade dos padecimentos que lhe são aplicados, a crueldade do destino que lhes é imposto, são - metaforicamente falando - todas as maneiras de exorcizar tais demônios interiores e queimá-los em efígie. As margens incriminadas servem de esgotos para onde os eflúvios inevitáveis, mas excessivos e venenosos, da sedução consumista são canalizados, de modo que as pessoas que conseguem permanecer no jogo do consumismo não se preocupam com o estado da própria saúde. (BAUMAN, 1998, p. 57).

Esses sujeitos criminalizados constituem o que Bauman (1998, p. 52) chama de fantasias dos perigo, ou seja, imagens que a sociedade gera a partir dos seus temores. Essas fantasias são fruto da própria ordem social, no caso de uma sociedade em que o sentimento de insegurança se amplia à medida em que a vigilância aumenta, posto que "A sociedade insegura da sobrevivência de sua ordem desenvolve a mentalidade de uma fortaleza sitiada" (1998, p. 52).

Para o autor, tanto mais poderosa a imagem destes "demônios interiores" na sociedade, tanto maior o desejo da maioria de ver "o crime punido" e a "justiça distribuída". Diante do sentimento crescente de insegurança, a resposta, nada eficaz, da sociedade moderna tem se dirigido contra os efeitos e muito pouco contra as causas crescentes de tal fenômeno. 


\section{DIREITO PENAL SIMBÓLICO}

O direito penal sempre esteve presente nas sociedade humanas. Na Antiguidade, existia uma profunda identidade entre religião e direito, de modo que as transgressões penais eram, em suma, transgressões religiosas. Na Modernidade, com a pretensão de construir-se um direito axiologicamente neutro, descolado das normas religiosas, o direito penal passou a tutelar os bens jurídicos mais elementares, aqueles absolutamente necessários ao exercício dos direitos fundamentais do indivíduo.

O direito penal ganhou ares democráticos, apesar da permanência de uma cultura majoritariamente inquisitorial, cuja aplicação reclama a observância dos valores do Estado constitucional. Dessa forma, na lição de Zaffaroni, o direito penal constitui:

O conjunto de leis que traduzem normas que pretendem tutelar bens jurídicos, e que determinam o alcance de sua tutela, cuja violação se chama "delito", e aspira a que tenha como consequência uma coerção jurídica particularmente grave, que procura evitar o cometimento de novos delitos por parte do autor. (ZAFFARONI, 2006, p. 15).

Diante do crescimento do índice de crimes e da sensação de insegurança, muitas vezes manipulada pelos veículos de comunicação de massa, ganha corpo a adoção de medidas que a doutrina convencionou chamar de Direito Penal Simbólico. Trata-se do fenômeno que se apresenta diante de casos que envolvem a aplicação da lei penal e que são exaustivamente explorado pelos meios de comunicação social. Diante desses casos, a "opinião pública" tem a impressão de que a lei penal existente é inócua ou insuficiente e, portanto, reclama o endurecimento das normas.

Ora, sempre que o cometimento de um determinado crime é associado à ideia de "clamor público", logo surgem propostas de majoração das penas para o tipo penal incurso. Normalmente, tais discussões vêm desacompanhadas de um processo de maturação social e legislativa, daí porque se constituir este em um direito de emergência.

A sociedade de consumo é também a sociedade do espetáculo, onde os programas de TV exibem corpos estendidos no chão, perseguições policiais e documentários intrincados sobre o cometimento de delitos. Neste contexto, os mais diversos comentadores se arvoram a proferir conclusões de cunho criminalístico que, a despeito da total ausência de embasamento teórico, terminam por formar o pensamento da coletividade.

Para Luiz Flávio Gomes (2007), o discurso midiático é atemorizador, isto porque: 
[...] ele não só apresenta como espetaculariza e dramatiza a violência. Não existe imagem neutra. Tudo que ela apresenta tem que chocar, tem que gerar impacto, vibração, emoção. Toda informação tem seu aspecto emocional: nisso é que reside a dramatização da violência. Não se trata de uma mera narração, isenta.

Esse discurso é fértil ao surgimento de uma legislação penal simbólica. Por isso mesmo, ganham corpo as propostas legislativas que tendem a subtrair direitos fundamentais, a criar novos e mais robustos tipos penais e a fortalecer o aparato policial e carcerário - é o direito penal de emergência atuando em sua plenitude.

[...] emergência vai significar aquilo que foge dos padrões tradicionais de tratamento pelo sistema repressivo, constituindo um subsistema de derrogação dos cânones culturais empregados na normalidade. Num certo sentido a criminologia contemporânea dá guarida a esse subsistema, colocando-o na escala mais elevada de gravidade criminosa a justificar a adoção de mecanismos excepcionais a combatê-la, embora sempre defenda o modelo de "estado democrático e de direito" como limite máximo da atividade legiferante nessa seara. (CHOUKR, 2002, p. 5-6).

Esse direito de emergência é chamado simbólico porque ignora as causas da criminalidade, e age criando a falsa impressão de que o simples endurecimento da lei, ou a supressão de garantias, irá garantir maior segurança:

\begin{abstract}
Assim, portanto, haverá de ser entendida a expressão "direito penal simbólico", como sendo o conjunto de normas penais elaboradas no clamor da opinião pública, suscitadas geralmente na ocorrência de crimes violentos ou não, envolvendo pessoas famosas no Brasil, com grande repercussão na mídia, dada a atenção para casos determinados, específicos e escolhidos sob o critério exclusivo dos operadores da comunicação, objetivando escamotear as causas históricas, sociais e políticas da criminalidade, apresentando como única resposta para a segurança da sociedade a criação de novos e mais rigorosos comandos normativos penais. (DUARTE NETO, 2009)
\end{abstract}

A legislação penal simbólica, apesar de vir ao encontro de interesses socialmente valorados e demonstrar uma certa capacidade de ação do Estado, em verdade ignora a solução prática dos conflitos, posto que não vai à raiz do problema, deixando de lado a pretensão do direito penal de ser a ultima ratio do direito.

Segundo Leonardo Sica (2002), o quadro de emergência penal tem seu cenário ideal de desenvolvimento em uma sociedade acuada e amedrontada (tal qual delineado no pensamento de Bauman), por meio de uma sensação de pânico, fruto de informações distorcidas divulgadas pela mídia.

A partir desse medo generalizado, então, "o legislador penal, desidioso ou astuto e desobrigado de atender qualquer desígnio de Política Criminal (inexistente), cede à tentação 
populista de oferecer o Direito Penal como panaceia de todos os males que a afligem" (SICA, 2002, p. 82).

A sensação latente de insegurança e que, portanto, "algo precisa ser feito", conduz, naturalmente, à crítica do sistema de garantias constitucionais, como se entraves fossem no combate à criminalidade.

A verdade, entretanto, é que o Direito Penal Simbólico, justamente por ser simbólico, é incapaz de apresentar respostas ao complexo problema da insegurança. Como o problema permanece, o clamor social é realimentado, exigindo mais e mais leis, como se a mera criação de leis penais pudesse trazer tranquilidade social.

\section{CONSIDERAÇÕES FINAIS}

Diante do contexto social da Modernidade Líquida, o fenômeno crime se revela uma variável fundamental na compreensão da sociedade e da ética que lhe é ínsita. É que para Bauman, o sentimento de insegurança, corrente na sociedade contemporânea, não seria um efeito indesejável, mas uma consequência necessária da sociedade de consumo.

A sensação de insegurança, em larga medida, é alimentada pelos veículos de comunicação social, que ao apresentar dados e informações, não partilham de uma despretensiosa neutralidade, ao contrário, possuem papel decisivo na disseminação do medo e do estranhamento.

O medo e a sensação de insegurança fazem reclamar uma atuação forte e incisiva do Estado no combate à criminalidade, mediante o endurecimento de leis e a adoção de estratégias de repressão, que repercutem na criação de um direito de emergência, pouco amadurecido e incapaz de enfrentar as raízes da insegurança generalizada.

A proposta de um Direito Penal Simbólico, tendente a ampliar, de forma desmedida, o poder punitivo do Estado, tem se revelado inócua, na medida em que o aumento das penas e do encarceramento continuam sendo acompanhados do aumento da criminalidade e da insegurança.

Faz-se necessário lançar um olhar crítico sobre as causas históricas, sociais e políticas da criminalidade e, em tal ponto, a contribuição de Bauman é fundamental na análise das raízes ideológicas da Modernidade e na construção do cenário contemporâneo. 
Se a origem do cenário de insegurança está, inexoravelmente, ligada ao modelo da Sociedade de Consumo, e ao processo de fragmentação e alheamento que esta produz, a transformação do quadro atual passa distante das medidas simbólicas de jaez penal. É certo que o fenômeno criminológico e o sentimento de insegurança possuem causas complexas, mas o seu enfrentamento, em uma perspectiva que busque atingir as causas, e não apenas os efeitos, passa pela ideia de refundação do paradigma ético da Modernidade.

\section{REFERÊNCIAS}

BAUMAN, Zygmunt. Comunidade: a busca por segurança no mundo atual. Tradução de Plínio Dentzien. Rio de Janeiro: Jorge Zahar, 2003.

Ética pós-moderna. Tradução de João Rezende Costa. São Paulo: Paulus 1997.

Legisladores e intérpretes: sobre modernidade, pós-modernidade e intelectuais. Tradução de Renato Aguiar. Rio de Janeiro: Jorge Zahar, 2010.

Modernidade líquida. Tradução de Plínio Dentzien. Rio de Janeiro: Jorge Zahar, 2001 .

O mal-estar da Pós-Modernidade. Tradução de Mauro Gama e Cláudia Martinelli Gama. Rio de Janeiro: Jorge Zahar, 1998.

CHOUKR, Fauzi Hassan. Processo Penal de Emergência. Rio de Janeiro: Lumen Juris. 2002.

DUARTE NETO, Júlio Gomes. O Direito Penal simbólico, o Direito Penal mínimo e a concretização do garantismo penal. In: Âmbito Jurídico, Rio Grande, XII, n. 66, jul 2009. Disponível em: <http://www.ambitojuridico.com.br/site/index.php?n_link=revista_artigos_leitura\&artigo_id=6154 >. Acesso em: 8 set. 2017. 
GOMES, Luiz Flávio. Mídia, segurança pública e Justiça criminal. Revista Jus Navigandi, ISSN 1518-4862, Teresina, ano 12, n. 1628, 16 dez. 2007. Disponível em: <https://jus.com.br/artigos/10768/midia-seguranca-publica-e-justica-criminal>. Acesso em: 8 set. 2017.

MASCARENHAS, Oacir Silva. A influência da mídia na produção legislativa penal brasileira. Âmbito Jurídico, Rio Grande, XIII, n. 83, dez 2010. Disponível em: $<$ http://www.ambitojuridico.com.br/site/?n_link=revista_artigos_leitura\&artigo_id=8727\&revista_caderno=3>. Acesso em 25 out. 2014.

SICA, Leonardo. O Direito Penal de Emergências e Alternativas à Prisão. São Paulo: RT, 2002.

ZAFFARONI, Eugenio Raúl; PIERANGELI, José Henrique. Manual de direito penal brasileiro: Parte Geral. 6. ed. v.1. São Paulo: RT, 2006.

\title{
SYMBOLIC CRIMINAL LAW IN LIQUID MODERNITY: CRIMINOLOGICAL ESSAY IN BAUMANIAN PERSPECTIVE
}

\begin{abstract}
The work of the Polish sociologist Zygmunt Bauman has as a characteristic note the thesis that we live in a Liquid Modernity, marked by the fluidity and instability of institutions and relations. In this context, with marked fragmentation, individualism and isolation, a scenario of generalized insecurity emerges, which has as a background the growth of crime, leading to a growth in the rate of imprisonment and a hardening of criminal standards, as a result of a process that the doctrine calls it "Symbolic Criminal Law," which ignores the real historical, social and political causes of the crime phenomenon. The present paper draws a relation between the theoretical postulates of Bauman and some criminological propositions, with a view to the construction of a critical and dialogical positioning for the understanding of the conjuncture posta. It addresses the right of emergency and symbolic penal legislation in dialogue with the lessons of Bauman on the ethics of Modernity.
\end{abstract}

Keywords: Criminology. Symbolic Criminal Law. Liquid Modernity. Consumer Society. Insecurity. 